\title{
Microdialysis Route of Administration
}

National Cancer Institute

\section{Source}

National Cancer Institute. Microdialysis Route of Administration. NCI Thesaurus. Code C150889.

Administration through perfusion liquid. 